\title{
DEVELOPMENT OF INORGANIC CONDENSED PHOSPHATE CATALYSTS FOR DECOMPOSITION OF GLOBAL WARMING GAS
}

\author{
Hiroaki ONODA* \\ (Corresponding author; onoda@fukui.kyoto-u.ac.jp) \\ Department of Materials Science and Engineering, Faculty of Engineering, \\ Kyoto University, Yoshida-Honmachi, Sakyo-ku, Kyoto 606-8501, Japan
}

Keywords; aluminum phosphates, nickel phosphates, decomposition of global warming gas, addition of metal cation, mechanochemical reforming

Abstract: Aluminum and nickel ortho- and condensed phosphates were used as a catalyst for decomposition of trifluoromethane and nitrogen trifluoride. The specific surface area, acid strength, and amount of acidic sites of phosphates were also estimated. The condensation degree of phosphates, the addition of other metal cation, and the reforming by mechanical treatment were discussed on the catalytic activity of the phosphates for the design of catalyst.

(Received March 1, 2006; Accepted December 15, 2006)

\section{INTRODUCTION}

It is well known that one of the serious problems is the global warming. As the substitute of chlorofluorocarbon, the use of trifluoromethane, nitrogen trifluoride, and so on, has recently increasing. These gases have the high global warming potential, therefore we have to build up the process to save and decompose ${ }^{1}$. Some novel catalysts for decomposition of the gases have been studied in the view of prevention of global warming ${ }^{2,3}$. The catalysts were required the high conversion of global warming gas, the high selectivity to low warming potential and harmless compounds, and long catalytic lifetime for the application.

Phosphates have been used for ceramic materials, catalysts, fluorescent materials, dielectric substances, metal surface treatment, manure, detergent, food additives, fuel cells, pigments, etc. 4-6. It is well known that aluminum phosphates work in various reactions as acidic catalysts. Transition metal phosphates were also used, among transition metal phosphates, nickel phosphates as well as copper phosphates have higher catalytic activity ${ }^{7}$.

Phosphates are transformed to other forms of phosphates in hydrolysis and dehydration reactions at elevated temperatures 8-10. Polyphosphate, cyclo-phosphate, and ultraphosphate are included in a group of condensed phosphates. Polyphosphate has a chain structure in which the $\mathrm{PO}_{4}$ unit shares two oxygen atoms; cyclo-phosphate has a cyclic structure; and ultraphosphate has a network structure.

The addition of some metal cation gives higher functional properties to the material. In previous work, formation of binary cyclo-tetraphosphates was studied about replacing copper or magnesium with rare earth elements in synthesis of cyclo-tetraphosphates 11. Further, the surface properties of the mixed phosphates were investigated to clarify the role of rare earth elements. It was observed in copper salt that the thermal product changed from cyclo-tetraphosphate to pyrophosphate by the addition of rare earth element. This change depended on the kind of rare earth element added. In magnesium salt, magnesium cyclo-tetraphosphate was formed in spite of the addition of rare earth element. Magnesium cyclo-tetraphosphate showed increasing amounts of acidic sites due to the addition of rare earth elements. The addition of metal cations had some influence on the formation and properties of condensed phosphates.

The reforming of solid surface gives the powder higher functional properties. There are many kinds of reforming, coating, topochemical method, mechanical treatment, ultraviolet irradiation, etc. The physical and chemical 
properties of solid materials change by crushing, pressing, milling, and other mechanical treatments. These phenomena are known as mechanochemical effects, comprises of the increase of specific surface area, defects and strain, and the cleavage of chemical bonds, and so on. For these effects, mechanically treated materials are regarded as being in an active state. In previous works ${ }^{12}$, neodymium ultraphosphate obtained higher functional properties as a catalyst by mechanochemical reforming.

In this report, the catalytic properties of various aluminum and nickel phosphates for decomposition of global warming gases, trifluoromethane and nitrogen fluoride, were discussed on the condensation degree of phosphates, the addition of metal cation, and the mechanochemical reforming.

\section{ALUMINUM PHOSPHATES}

\section{Condensation degree of aluminum phosphates}

Aluminum orthophosphate had about 100 $\mathrm{m}^{2} \cdot \mathrm{g}^{-1}$ of specific surface area, on the other hand, polyphosphate had smaller one than $1 \mathrm{~m}^{2} \cdot \mathrm{g}^{-1} 13$. The acid strength of aluminum orthophosphate was between -5.6 and -3.0 in $\mathrm{pKa}$ unit. Aluminum polyphosphate had the acid strength between +3.3 and +1.5 . Figure 1 shows the conversion of trifluoromethane over aluminum ortho- and poly-phosphates. Aluminum orthophosphate had high conversion at lower temperature than aluminum polyphosphate. However, this aluminum orthophosphate had shorter catalytic lifetime than 5 hours on the decomposition of trifluoromethane.

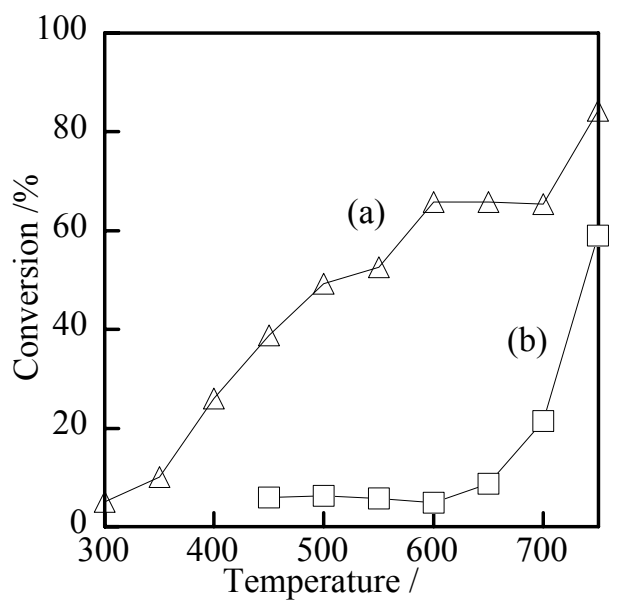

Fig. 1. Conversion of trifluoromethane over aluminum orthophosphate (a) and aluminum polyphosphate (b).

\section{Addition of metal cation to aluminum phosphates}

To improve catalytic activity and life, the addition of rare earth cation to $\mathrm{AlPO}_{4}$ was investigated. About twenty percent of specific surface area had improved by the addition of neodymium and cerium. The amount of acidic sites of phosphates heated at $800^{\circ} \mathrm{C}$ is shown in Figure 2. The addition of rare earth cation improved the strong range at $+1.5 \geq \mathrm{pKa}>-5.6$. Figure 3 shows the conversion to $\mathrm{CO}_{2}$ over rare earth added aluminum orthophosphates. The conversion of trifluoromethane over all samples became smaller in short time. After the measurement at $500^{\circ} \mathrm{C}$ for 4 hours, aluminum and rare earth phosphates were crystallized. Because samples had heated at $800^{\circ} \mathrm{C}$ before the catalytic measurement, the contact with trifluoromethane and so on promoted the crystallization of the phosphates. The increase of amount of acidic sites on aluminum orthophosphate by the addition of metal cation is less suitable way to improve the catalytic activity and lifetime.

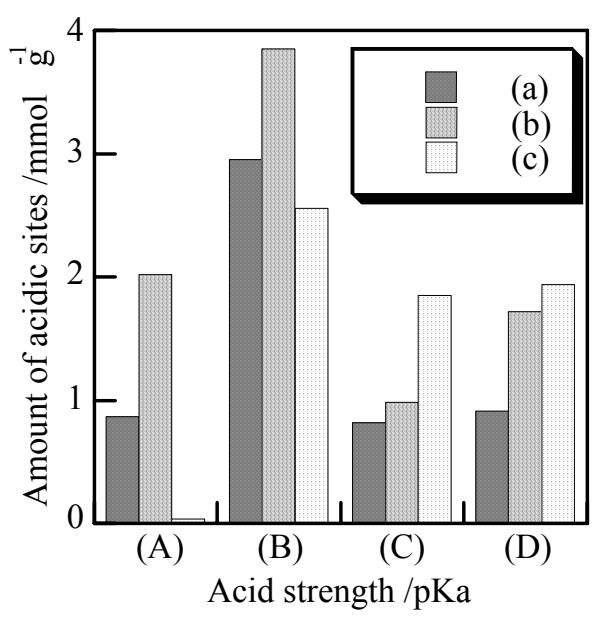

Fig. 2. Amount of acidic sites of rare earth doped aluminum orthophosphates heated at $800^{\circ} \mathrm{C}$, (a) undoped, (b) $\mathrm{Ce} / \mathrm{Al}=1 / 9$, and (c) $\mathrm{Nd} / \mathrm{Al}=1 / 9$, (A) $+3.3<\mathrm{pKa} \leq+4.8, \quad$ (B) $\quad+1.5<\mathrm{pKa} \leq+3.3$, $-3.0<\mathrm{pKa} \leq+1.5$, and (D) $-5.6<\mathrm{pKa} \leq-3.0$.

\section{Mechanochemical reforming of aluminum phosphates}

It was reported that the acid strength, amount of acidic sites, and catalytic activities were improved, because mechanochemical treatment caused the clearvage of $\mathrm{P}-\mathrm{O}-\mathrm{P}$ bonding in ultraphosphate to $\mathrm{P}-\mathrm{O}-\mathrm{H}$ bonding 12 Therefore, the condensed phosphate had a possibility to improve the catalytic activity by mechanical treatment. As another method to improve catalytic activities, aluminum polyphosphate was treated with planetary mill ${ }^{14}$.

Figure 4 shows the specific surface area and amounts of acidic sites of samples. The specific surface area extremely increased in early $30 \mathrm{~min}$ and then slowly increased. The phosphate milled for $360 \mathrm{~min}$ had maximum specific surface area. The mechanical treatment produced the acidic sites 


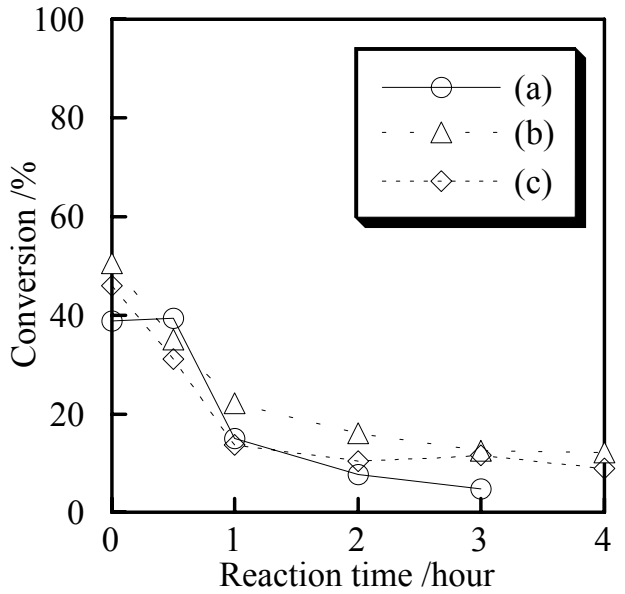

Fig. 3. Conversion of trifluoromethane over rare earth doped aluminum orthophosphate, (a) undoped, (b) $\mathrm{Ce} / \mathrm{Al}=1 / 9$, and (c) $\mathrm{Nd} / \mathrm{Al}=1 / 9$.

at $\mathrm{pKa} \leq+1.5$ on surface of aluminum polyphosphate powder. A small part of P-O-P bonding in polyphosphate was considered to cleavage to $\mathrm{P}-\mathrm{O}-\mathrm{H}$ bonding with $\mathrm{H}_{2} \mathrm{O}$ in air ${ }^{12}$. The amounts of acidic sites also improved to $360 \mathrm{~min}$ and then declined. The increase of specific surface area and $\mathrm{P}-\mathrm{O}-\mathrm{H}$ bonding caused the improvement of the amount of acidic sites. In the long milling time, the cohesion by $\mathrm{P}-\mathrm{O}-\mathrm{H}$ bonding made specific surface area and amount of acidic sites decreased. Because these changes were due to a small part of P-O-P bonding in polyphosphate, the change was less observed in IR spectra.

Figure 5 shows the conversion of trifluoromethane over aluminum polyphosphate milled for several minutes. The phosphate milled

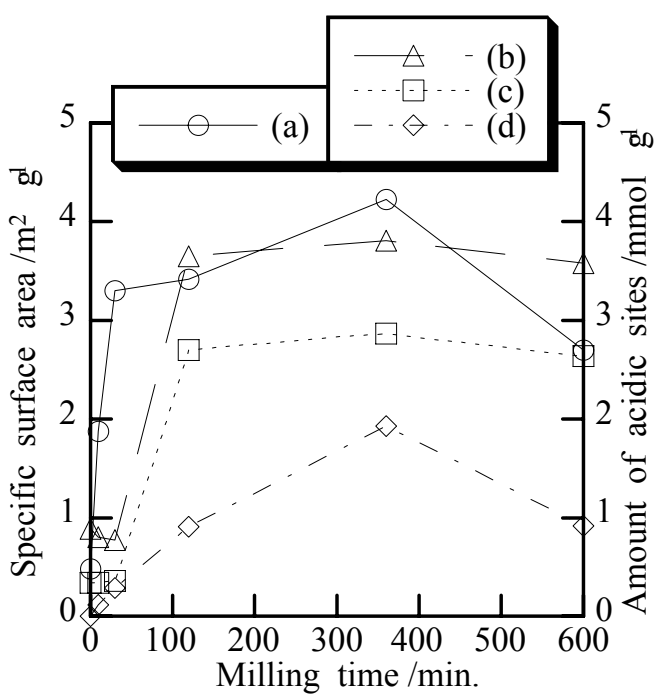

Fig. 4. Specific surface area and amount of acidic sites of aluminum polyphosphates milled for several minutes, (a) specific surface area, (b) amount of acidic site at $\mathrm{pKa} \leq+4.8$, (c) $\mathrm{pKa} \leq+3.3$, and (d) $\mathrm{pKa} \leq+1.5$.

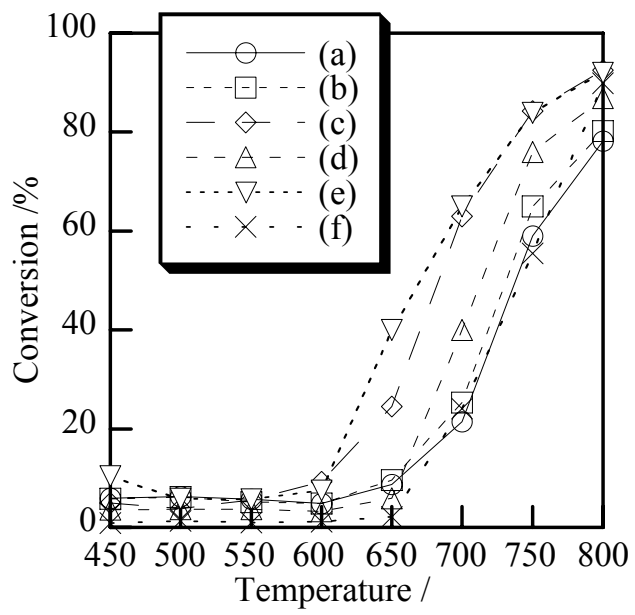

Fig. 5. Conversion of trifluoromethane to $\mathrm{CO}_{2}$ over aluminum polyphosphate milled for several minutes.

for $360 \mathrm{~min}$ indicated high conversion at lower temperature than others. On the other hand, sample milled for $600 \mathrm{~min}$ had low catalytic activity. The results were corresponding with the tendency of specific surface area and amount of acidic sites.

By mechanochemical reforming, aluminum polyphosphate became to have lower crystallinity, smaller particle size, and larger specific surface area. The acid strength became stronger than $\mathrm{pKa}=+3.3$ and the amounts of acidic sites increased. The catalytic properties of aluminum polyphosphate were also improved by mechanical treatment. However, this improvement was less sufficient for catalytic application for decomposition of trifluoromethane.

\section{NICKEL PHOSPHATES}

\section{Condensation degree of nickel phosphates}

Transition metal phosphates were used as acid catalyst like aluminum phosphates in many kinds of reactions. In the group of transition metal phosphates, copper and nickel salts had relatively high catalytic activity . In this work, nickel phosphates were estimated as one group of transition metal phosphates. Nickel phosphates had smaller specific surface area than $10 \mathrm{~m}^{2} \cdot \mathrm{g}^{-1}$. Specific surface areas of nickel phosphates had influence much on the calcined temperature less on the structures of phosphates. The maximum acid strength of nickel ortho- and pyro-phosphates heated at $1000^{\circ} \mathrm{C}$ was between $\mathrm{pKa}=+4.8$ and +3.3. On the other hand, nickel cyclo-tetraphosphate had the acidic sites which were stronger than $\mathrm{pKa}=+1.5$. Acid strength of acidic sites on phosphate catalysts became stronger with condensation degree. Furthermore, the amount of acidic sites increased with condensation of phosphates. 


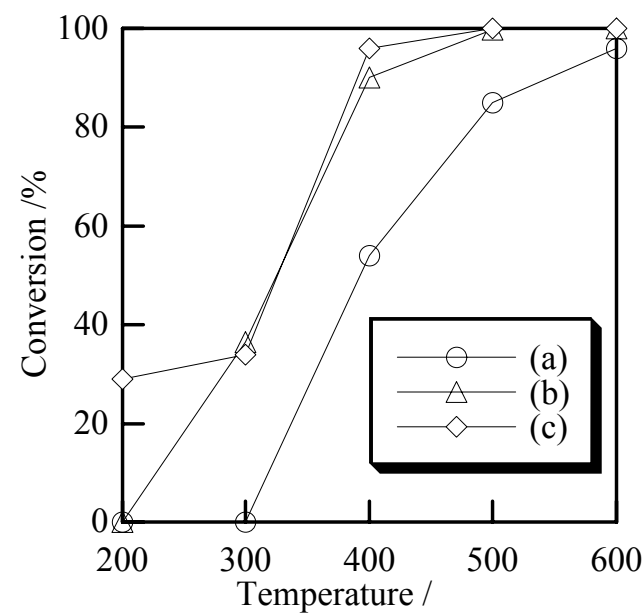

Fig. 6. Conversion of nitrogen trifluoride over various nickel phosphates, (a) orthophosphate, (b) pyrophosphate, and (c) cyclo-tetraphosphate.

Because nitrogen trifluoride is easier to decompose than trifluoromethane, the decomposition reaction of nitrogen trifluoride was used to estimate the catalytic activity of various nickel phosphates. Figure 6 shows the catalytic activity of various nickel phosphates on decomposition reaction of nitrogen trifluoride. Nickel condensed phosphates had higher catalytic activity than nickel orthophosphate. Nickel cyclo-tetraphosphate is much condensed than pyrophosphates. The catalytic activity became higher with condensation degree of phosphates.

\section{Addition of metal cation to nickel phosphates}

Figure 7 shows the specific surface area and amount of acidic sites of nickel pyrophosphate added various metal cation in $\mathrm{M} / \mathrm{Ni}=2 / 8$ heated at $800^{\circ} \mathrm{C}$. The maximum acid strength of large number of materials was between +3.3 and +4.8 in $\mathrm{pKa}$ units. The neodymium added sample had stronger acidic sites than others, because the maximum acid strength of $\mathrm{NdPO}_{4}$ was between -3.0 and +1.5 in $\mathrm{pKa}$ units 4 . The addition of $\mathrm{Mg}$, $\mathrm{Co}$, and $\mathrm{Cu}$ improved the specific surface area and increased the amount of acidic sites at $+3.3<\mathrm{pKa} \leq+4.8$. On the other hand, the specific surface area of nickel pyrophosphate decreased by the addition of yttrium and neodymium. Yttrium and neodymium polyphosphates, $\mathrm{Y}\left(\mathrm{PO}_{3}\right)_{3}$ and $\mathrm{Nd}\left(\mathrm{PO}_{3}\right)_{3}$, were considered to form, because $\mathrm{Y}\left(\mathrm{PO}_{3}\right)_{3}$ and $\mathrm{Nd}\left(\mathrm{P}_{2}\right)_{3}$ had smaller specific surface areas than $1 \mathrm{~m}^{2} \mathrm{~g}{ }^{-1} \cdot \mathrm{YPO}_{4}$ and $\mathrm{NdPO}_{4}$, confirmed from XRD patterns, had larger specific surface areas than $20 \mathrm{~m}^{2} \square \mathrm{g}^{-1}$.

Figure 8 shows the conversion to $\mathrm{CO}_{2}$ over samples prepared in $\mathrm{M} / \mathrm{Ni}=2 / 8$ heated at $800^{\circ} \mathrm{C}$. Nickel pyrophosphate had enough catalytic activity for decomposition of trifluoromethane over $650^{\circ} \mathrm{C}$.

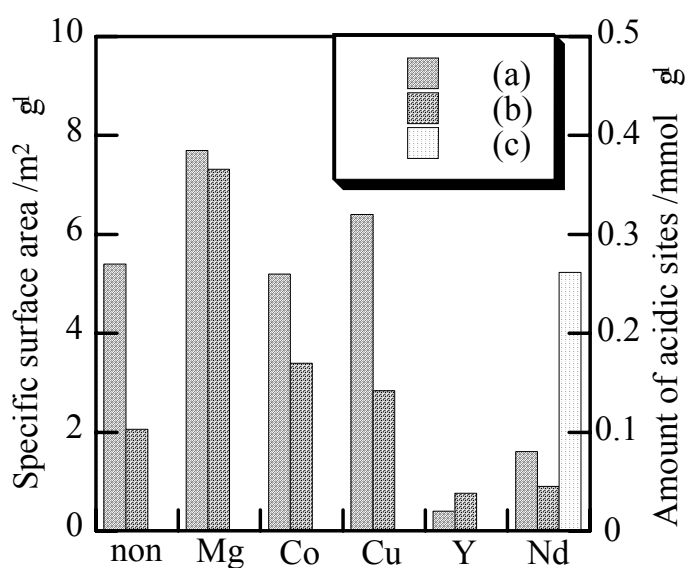

Fig. 7. Specific surface areas and amounts of acidic sites of samples prepared in $\mathrm{M} / \mathrm{Ni}=2 / 8$ heated at $800^{\circ} \mathrm{C}$ : (a) specific surface area, (b) amount of acidic sites at $+3.3<\mathrm{pKa} \leq+4.8$, and (c) at $+1.5<\mathrm{pKa} \leq+3.3$.

The addition of $\mathrm{Mg}, \mathrm{Cu}$, or $\mathrm{Co}$ improved the catalytic activity of $\mathrm{Ni}_{2} \mathrm{P}_{2} \mathrm{O}_{7}$ at lower temperature. On the other hand, the catalytic activity became lower due to the addition of $\mathrm{Nd}$ and $\mathrm{Y}$. The conversion to $\mathrm{CO}_{2}$ was considered to be related with the specific surface area and the amount of acidic sites at $+3.3<\mathrm{pKa} \leq+4.8$.

Figure 9 shows the conversion of trifluoromethane and selectivity to $\mathrm{CO}_{2}$ over magnesium doped nickel pyrophosphate in $\mathrm{Mg} / \mathrm{Ni}=2 / 8$ and $\mathrm{AlPO}_{4} . \mathrm{AlPO}_{4}$ had high conversion of trifluoromethane at first time. The conversion over $\mathrm{AlPO}_{4}$ became lower in 5 hours. The selectivity to $\mathrm{CO}_{2}$ over $\mathrm{AlPO}_{4}$ decreased to about $6 \%$ in 5 hours. Because the compounds, that have a

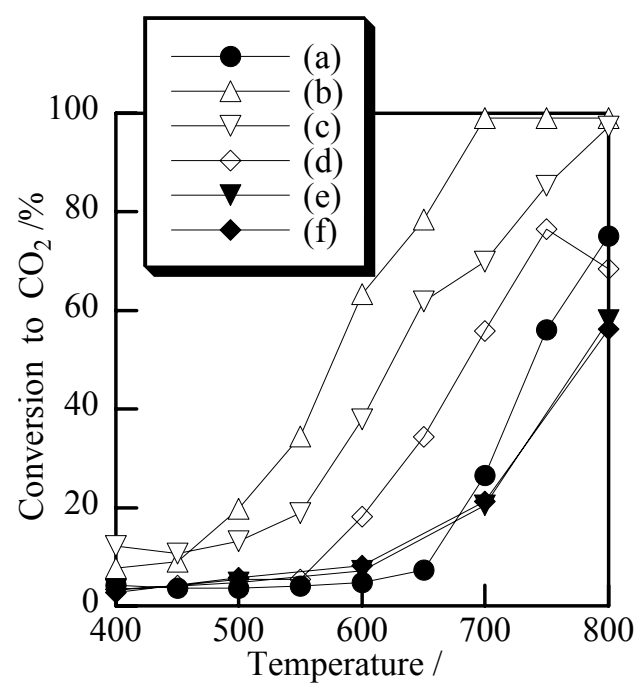

Fig. 8. Conversion to $\mathrm{CO}_{2}$ over samples prepared in $\mathrm{M} / \mathrm{Ni}=2 / 8$ heated at $800^{\circ} \mathrm{C}$ : (a) non-added, (b) $\mathrm{Mg}$, (c) $\mathrm{Co}$, (d) $\mathrm{Cu}$, (e) $\mathrm{Y}$, and (f) $\mathrm{Nd}$. 


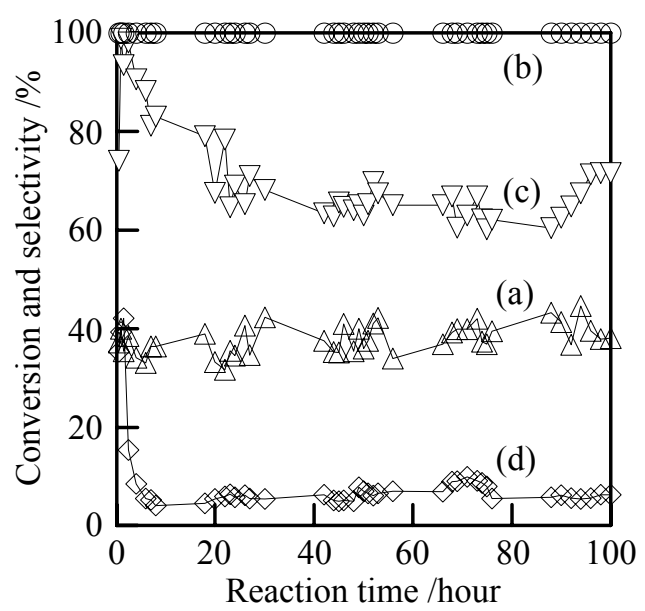

Fig. 9. Conversion of trifluoromethane and selectivity to $\mathrm{CO}_{2}$ over magnesium doped nickel pyrophosphate in $\mathrm{Mg} / \mathrm{Ni}=2 / 8$ ((a) conversion, (b) selectivity) and $\mathrm{AlPO}_{4}$ ((c) conversion, (d) selectivity).

possibility to be produced in the decomposition of trifluoromethane, have high global warming potential, $\mathrm{CO}_{2}$ is better product in this catalytic reaction. On the other hand, magnesium doped nickel pyrophosphate in $\mathrm{Mg} / \mathrm{Ni}=2 / 8$ kept the constant conversion of trifluoromethane at about $40 \%$. The pyrophosphate catalyst preserved about $100 \%$ of selectivity to $\mathrm{CO}_{2}$ for a long time. $\mathrm{AlPO}_{4}$ had higher catalytic activity than the pyrophosphate only for short times. The magnesium doped nickel pyrophosphate catalyst in $\mathrm{Mg} / \mathrm{Ni}=2 / 8$ had much larger conversion to $\mathrm{CO}_{2}$ than $\mathrm{AlPO}_{4}$ for long times.

The revitalization of catalytic activity of $\mathrm{AlPO}_{4}$ was considered to be due to adsorption of carbon, polymer, and fluoride as products in the catalytic reaction. The peaks of aluminum fluoride were observed in XRD pattern of $\mathrm{AlPO}_{4}$ after use as a catalyst for long time. Furthermore, $\mathrm{AlPO}_{4}$ sample after use had a larger ratio of carbon than magnesium doped nickel pyrophosphate in $\mathrm{Mg} / \mathrm{Ni}=2 / 8$. The specific surface area of aluminum orthophosphate became much smaller during use as a catalyst for decomposition of trifluoromethane. These adsorbed carbon, polymer, and fluoride were considered to cover the pores of $\mathrm{AlPO}_{4}$.

Figure 10 shows the models of decomposition of trifluoromethane over magnesium doped nickel pyrophosphate catalyst in $\mathrm{Mg} / \mathrm{Ni}=2 / 8$ and $\mathrm{AlPO}_{4}$ at $500^{\circ} \mathrm{C}$. Because $\mathrm{AlPO}_{4}$ had much stronger acidic sites than magnesium doped nickel pyrophosphate catalyst, trifluoromethane was strongly adsorbed on the surfaces of the catalyst. In the case of the existence of trifluoromethane nearby, a coupling reaction would occur to polymer on the surface of the catalyst. In the case of the absence of trifluoromethane, carbon was produced. Furthermore, aluminum fluoride was formed on the surface of the catalyst. These carbon, polymer, and fluoride molecules covered the pores of $\mathrm{AlPO}_{4}$ and acidic sites on the surface. Therefore, the catalytic activity of $\mathrm{AlPO}_{4}$ became smaller in a short time. On the other hand, magnesium doped nickel pyrophosphate catalyst had only weak acidic sites. Trifluoromethane was weakly adsorbed at an acidic site and decomposed to $\mathrm{CO}_{2}$. Carbon, polymer, and fluoride were difficult to form and then less likely to adsorb on surface of magnesium doped nickel pyrophosphate catalyst. Therefore, magnesium doped nickel pyrophosphate catalyst in $\mathrm{Mg} / \mathrm{Ni}=2 / 8$ exhibited stable high selectivity to $\mathrm{CO}_{2}$ at $500^{\circ} \mathrm{C}$ for long time.

The small addition of magnesium, cobalt, or copper to nickel pyrophosphate improved the catalytic activity for decomposition of

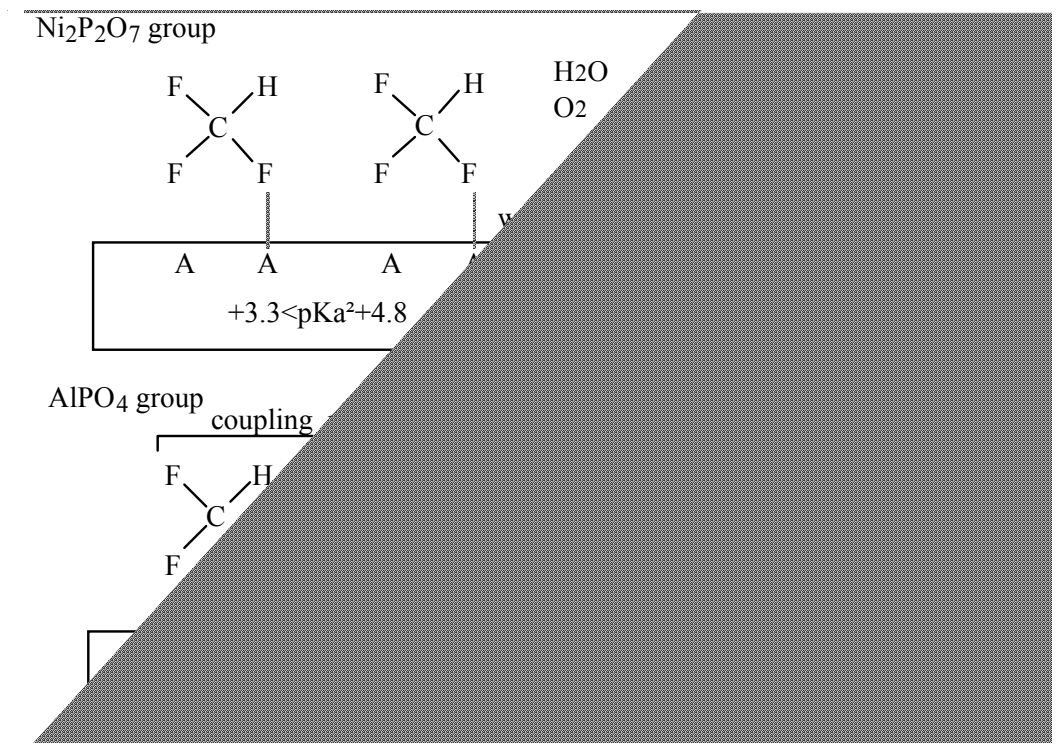

Fig.10. Models of decomposition reaction of trifluoromethane over $\mathrm{Ni}_{2} \mathrm{P}_{2} \mathrm{O}_{7}$ and $\mathrm{AlPO}_{4}$ groups. 
trifluoromethane to $\mathrm{CO}_{2}$. The conversion to $\mathrm{CO}_{2}$ was related with the specific surface areas and the amounts of acidic sites at $+3.3<\mathrm{pKa} \leq+4.8$. These nickel pyrophosphate catalysts had the suitable catalytic activity at $500^{\circ} \mathrm{C}$ for a long time. The selectivity to $\mathrm{CO}_{2}$ was almost $100 \%$ in that condition. There was no revitalization due to carbon, polymer, or fluoride adsorbed on surfaces of catalysts. Novel nickel pyrophosphate catalysts had effective catalytic activity for decomposition of trifluoromethane.

\section{Mechanochemical reforming of nickel phosphates}

Figure 11 shows the specific surface area and amount of acidic sites at $+3.3<\mathrm{pKa} \leq+4.8$ of $\mathrm{Ni}_{2} \mathrm{P}_{2} \mathrm{O}_{7}$ treated for several minutes ${ }^{17}$. The specific surface area of $\mathrm{Ni}_{2} \mathrm{P}_{2} \mathrm{O}_{7}$ became large from 5.5 to $10.8 \mathrm{~m}^{2} \cdot \mathrm{g}^{-1}$ by short time milling. By milling for a long time, that became smaller. By milling, the particles were considered to be minuteness and then to cohere, finally to be in equilibrium. The stronger acidic sites than $\mathrm{pKa}=+3.3$ did not appear on $\mathrm{Ni}_{2} \mathrm{P}_{2} \mathrm{O}_{7}$ particles by mechanochemical treatment. The sample milled for $120 \mathrm{~min}$ had large amount of acidic sites at $+3.3<\mathrm{pKa} \leq+4.8$. There was the relationship between specific surface area and amount of acidic sites at $+3.3<\mathrm{pKa} \leq+4.8$. All samples had about $0.02 \mathrm{mmol} \cdot \mathrm{m}^{-2}$ of amount of acidic sites at $+3.3<\mathrm{pKa} \leq+4.8$ per specific surface area. The changes of the amounts of acidic sites depended much on the specific surface area of phosphate, in other words, the powder condition. By milling, the P-O-P bonding in $\mathrm{Ni}_{2} \mathrm{P}_{2} \mathrm{O}_{7}$ was considered less to cleavage to $\mathrm{P}-\mathrm{O}-\mathrm{H}$ bonding with $\mathrm{H}_{2} \mathrm{O}$ in air as following equation.

$\mathrm{Ni}_{2} \mathrm{P}_{2} \mathrm{O}_{7}+\mathrm{H}_{2} \mathrm{O} \rightarrow 2 \mathrm{NiHPO}_{4}$

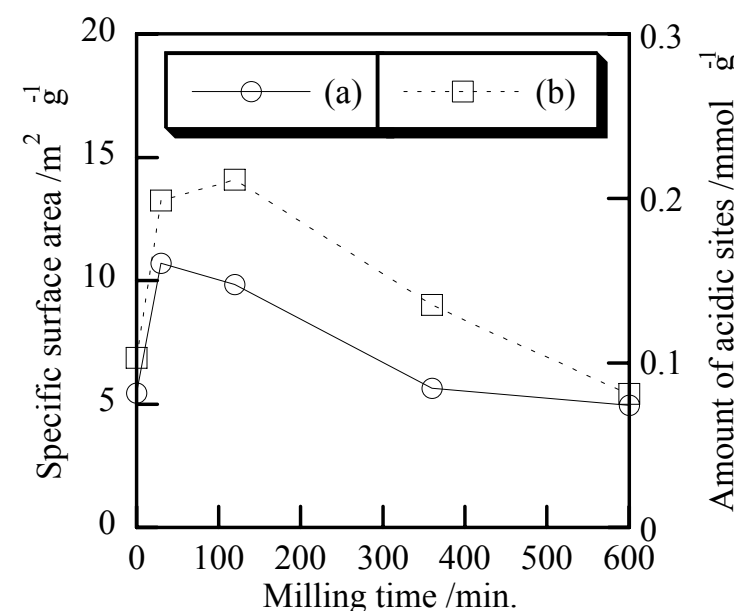

Fig. 11. Specific surface area (a) and amount of acidic sites at $+3.3<\mathrm{pKa} \leq+4.8$ (b) of $\mathrm{Ni}_{2} \mathrm{P}_{2} \mathrm{O}_{7}$ treated for several minutes.
The increase of the amount of acidic sites was expected to improve the acidic catalytic activity of nickel pyrophosphate. By mechanochemical treatment, the conversion of $\mathrm{CHF}_{3}$ over $\mathrm{Ni}_{2} \mathrm{P}_{2} \mathrm{O}_{7}$ became lower. On the other hand, the selectivity to $\mathrm{CO}_{2}$ was improved. Because the milled samples had a little stronger acidic sites than the pyrophosphate without milling, $\mathrm{CHF}_{3}$ transformed much to carbon and polymer over $\mathrm{Ni}_{2} \mathrm{P}_{2} \mathrm{O}_{7}$. A small part of the formed carbon and polymer was adsorbed on the surface of phosphate powder. Therefore, the conversion of $\mathrm{CHF}_{3}$ became lower on samples with milling. On the other hand, the selectivity to $\mathrm{CO}_{2}$ was considered to improve with the increase of the amount of acidic sites at $+3.3<\mathrm{pKa} \leq+4.8$. In general, the conversion to $\mathrm{CO}_{2}$ became lower by mechanochemical treatment. Figure 12 shows the conversion of $\mathrm{CHF}_{3}$ to $\mathrm{CO}_{2}$ over $\mathrm{Ni}_{2} \mathrm{P}_{2} \mathrm{O}_{7}$ milled for several minutes. The catalytic activity on the decomposition reaction of trifluoromethane was reduced by this mechanochemical treatment. This reaction was considered to require much larger amount of acidic sites.

By mechanochemical reforming, nickel pyrophosphate began to have lower crystallinity, larger specific surface area, and smaller particle size. The acidic sites on surface of the material were little increased by cleavage of P-O-P bonding in mechanochemical reforming. The chemical structure of nickel pyrophosphate was relatively stable for mechanical treatment. The catalytic activity on the decomposition reaction of trifluoromethane had little change by this mechanochemical treatment. This reaction was considered to require much larger amount of acidic sites.

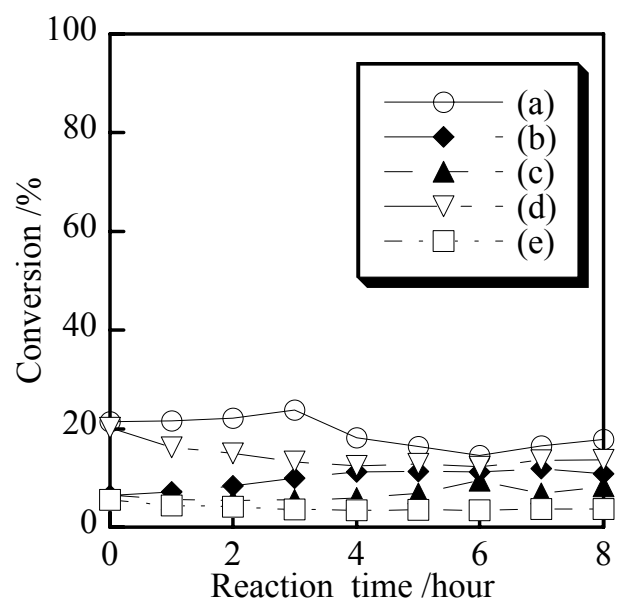

Fig. 12. Conversion of $\mathrm{CHF}_{3}$ to $\mathrm{CO}_{2}$ over $\mathrm{Ni}_{2} \mathrm{P}_{2} \mathrm{O}_{7}$ milled for several minutes, (a) $0 \mathrm{~min}$, (b) $30 \mathrm{~min}$, (c) $120 \mathrm{~min}$, (d) $360 \mathrm{~min}$, and (e) $600 \mathrm{~min}$. 


\section{CONCLUSION}

Aluminum orthophosphate had higher catalytic activity than aluminum polyphosphate. The catalytic activity of aluminum orthophosphate decreased in short time, drastically. The addition of transition metal cation and mechanochemical reforming on aluminum phosphates improved the catalytic activity, however did not improve the catalytic lifetime.

Nickel pyrophosphate had a little higher catalytic activity than nickel ortho- and cyclo-tetraphosphates. The addition of metal cation improved the catalytic activity of nickel phosphates. Magnesium doped nickel pyrophosphate had much longer catalytic lifetime than aluminum phosphates. The reforming of nickel pyrophosphate by mechanical treatment improved the specific surface area and the amount of acidic sites. However, the catalytic conversion had little change by mechanical treatment.

The high conversion and selectivity, and the longer catalytic lifetime were required as a catalyst. Totally, magnesium doped nickel pyrophosphate is suitable catalyst for decomposition of global warming gas. The material that has stronger acidic sites is not necessarily the better catalyst for any reactions.

\section{ACKOWLEDGEMENTS}

The author is grateful to Mr. Takafumi Ohta and Mr. Masakazu Kohno, Ritsumeikan University, Japan, for their help in these experiments. The author thanks Prof. Kazuyuki Hirao and Prof. Isao Tanaka, Kyoto University, Japan, for the Computational Materials Science Project in Kyoto University from the Ministry of Education, Culture, Sports, Science and Technology of Japan.

\section{REFERENCES}

1. Intergovernmental Panel on Climate Change, Third Assessment Report; Climate Change 2001.

2. Y. Takita, H. Wakamatsu, G.-L. Li, Y. Moro-oka, H. Nishiguchi, T. Ishihara, J. Molecul. Catal. A, 155, 111 (2000).

3. J. Y. Jeon, X.-F. Xu, M. H. Choi, H. Y. Kim, Y. K. Park, Chem. Commun., 1244 (2003).

4. H. Onoda, H. Nariai, A. Moriwaki, H. Maki, I. Motooka, J. Mater. Chem., 12(6), 1754 (2002).

5. H. Onoda, K. Yokouchi, K. Kojima, H. Nariai, Mater. Sci. Eng. B, 116(2), 189 (2005).

6. H. Onoda, K. Kojima, H. Nariai, J. All. Comp., 408-412, 568 (2006).

7. H. Nariai, H. Taniguchi, H. Maki, I. Motooka, Phosphorus Res. Bull., 8, 119 (1998).

8. M. T. Averbuch-Pouchat, A. Durif, Topics in Phosphate Chemistry, (World Scientific Publishing Co. Pte. Ltd., Singapore, 1996).
9. H. Onoda, A. Takenaka, K. Kojima, H. Nariai, Mater. Chem. Phys., 82(1), 194 (2003).

10. H. Onoda, D. Mori, K. Kojima, H. Nariai, Inorg. Mater., 41(10), 1089 (2005).

11. H. Onoda, H. Nariai, H. Maki, I. Motooka, Phosphorus Res. Bull., 12, 139 (2001).

12. H. Onoda, H. Nariai, H. Maki, I. Motooka, Phosphorus Res. Bull., 9, 69 (1999).

13. H. Onoda, M. Kohno, J. Tamaki, K. Kojima, H. Nariai, Multid. Model. Materi. Struc., 2(4), 463 (2006).

14. H. Onoda, M. Kohno, K. Kojima, Phos. Res. Bull., accepted.

15. H. Onoda, T. Ohta, J. Tamaki, K. Kojima, H. Nariai, Mater. Chem. Phys., 96(1), 163 (2006).

16. H. Onoda, T. Ohta, J. Tamaki, K. Kojima, Appl. Catal. A, 288(1-2), 98 (2005).

17. H. Onoda, T. Ohta, K. Kojima, Mater. Chem. Phys., 98(2-3), 363 (2006). 